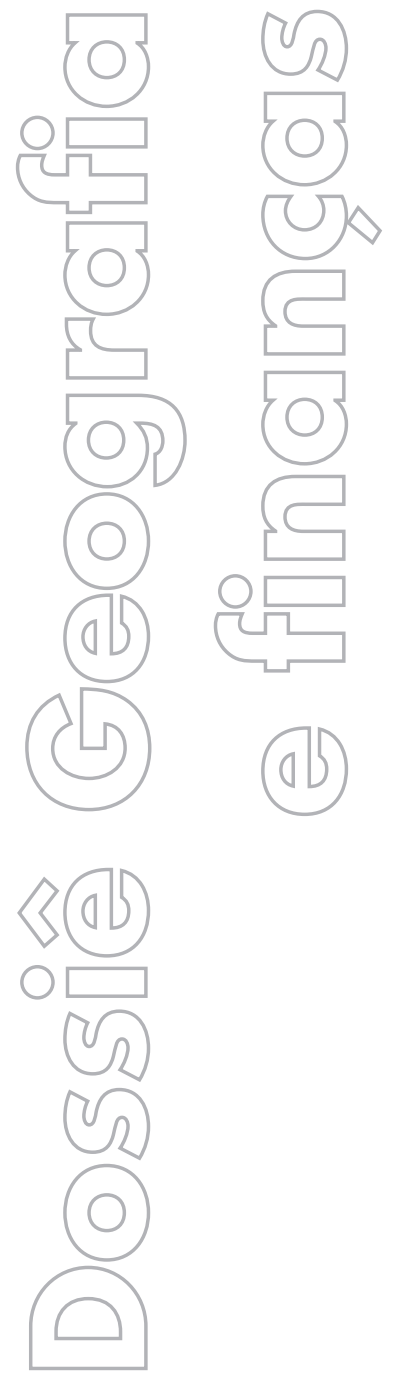

revista

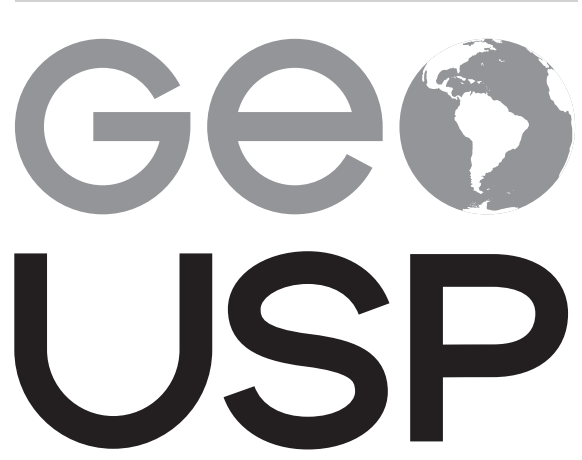

espaço e tempo

Volume $21 \cdot n^{\circ} 2$ (2017)

\section{Rede urbana, rede bancária e aspectos da topologia do sistema financeiro}

Tânia Maria Fresca

UEL

p. $443-461$

Como citar este artigo:

FRESCA, T. M. Rede urbana, rede bancária e aspectos da topologia do sistema financeiro. Geousp - Espaço e Tempo (Online), v. 21, n. 2, p. 443-461, agosto. 2017. ISSN 2179-0892.

Disponível em: < http://www.revistas.usp.br/geousp/ article/view/134532>. doi: 10.11606/issn.2179-0892. geousp.2017.134532.

\section{(c) $(1)(9$}

Este artigo está licenciado sob a Creative Commons Attribution 4.0 License. 


\title{
Rede urbana, rede bancária e aspectos da topologia do sistema financeiro
}

\section{Resumo}

Como se realiza o sistema bancário numa rede urbana regional? Mantém as mesmas tendências do sistema nacional ou responde a particularidades da rede urbana? A topologia do sistema financeiro é diferente da que se apresenta na escala nacional? Essas são algumas das questões que norteiam este trabalho. Num momento em que o sistema bancário sofre mudanças importantes, com expansão das redes controladas pelo capital privado nacional e internacional, em que aumenta a exclusão de cidades sem agências e postos de atendimento e em que serviços bancários ampliam-se segundo redes geográficas de comunicação e informação, verifica-se a expansão do sistema cooperativo de crédito. Vinculado à financeirização da produção agrícola, esse sistema de crédito ocupou áreas de forte produção de commodities, cuja realização precisa de agências bancárias.

Palavras-chave: Bancos comerciais múltiplos. Commodities. Norte do Paraná. Redes geográficas. Sistema cooperativo de crédito.

\section{The urban network, the banking network and aspects of the topology of the financial system}

\begin{abstract}
How is the banking system implemented in a regional urban network? Does it keep the same tendencies as the national system or does it correlate to the particularities of the urban network? From the point of view of the topology of the financial system, is there a differentiation from that which presents itself on a national scale? These are some of the questions that guide this work. At a time when there are big changes in the banking system, with an expansion of the networks controlled by national and international private capital, with increases in the exclusion of cities without branches and service points, in which banking services extend through geographical information and communication networks, there is an expansion of the cooperative credit system. This system has occupied areas of strong production of commodities, which require banks for their realization, linked to the financialization of agricultural production.
\end{abstract}

Keywords: Multiple commercial banks. Commodities. Northern Paraná. Geographical networks. Credit cooperative system. 


\section{Introdução}

Rede urbana, rede bancária e topologia do sistema financeiro são temáticas que, individualmente, contam com importante bibliografia na geografia brasileira, a discutirem diferentes aspectos e dinâmicas temporalmente distintas. No entanto, pesquisas que discutam articuladamente o sistema bancário em uma rede urbana regional ainda são poucas e se acrescentar aspectos da topologia, tornam-se escassas.

No momento atual, em que avança a financeirização da economia nacional articuladamente à global; em que o sistema bancário está cada vez mais sob o controle do capital privado nacional e internacional; com lógicas territoriais em direção a reduzirem presença de agências e postos de atendimentos em cidades de diferentes escalões urbanos; em que os bancos públicos estão reduzindo suas áreas de atuação mediante interrupção de investimentos, entre outros, tornam-se necessárias algumas reflexões a respeito de como tendências gerais se realizam singularizadamente.

Em linhas gerais, evidencia-se um aumento da exclusão de cidades sem agências, em momento de forte creditização do território (Santos, 1993), a obterem tal serviço apenas por postos de atendimentos bancários e/ou correspondentes postais. Entre as razões para essa exclusão, se destacam as fortes transformações que afetaram o sistema bancário desde meados dos anos 1990, correlacionados à dinâmica econômica nacional e particularmente à evolução do crédito no Brasil, bem como inovações no sistema de comunicação.

Assim, o presente trabalho realiza uma análise do sistema bancário presente na rede urbana do Norte do Paraná no período de 1997 a fevereiro de 2016, procurando evidenciar como as tendências gerais nacionais se realizam nessa rede urbana; inclui ainda aspectos da topologia do sistema financeiro presente nessa rede urbana, e efetua-se uma discussão a respeito do sistema cooperativo de crédito como uma possibilidade ao entendimento das razões pelas quais a rede urbana do Norte do Paraná não apresentou, até o momento pesquisado, redução dos serviços bancários.

Metodologicamente, o trabalho apoiou-se em levantamentos de dados secundários no Banco Central do Brasil (BCB, 2016a, 2016b), na Bolsa Brasileira de Mercadorias (2016), na BMEFBovespa (2016), no Instituto Brasileiro de Geografia e Estatística (IBGE, 2000, 2008), no Sicredi (Portal do Cooperativismo Financeiro, 2016c), no Sicoob (Portal do Cooperativismo Financeiro, 2016b), na Uniprime (2016), entre outros, para obtenção de informações sobre número de agências e postos diversos de atendimentos bancários. Inclui-se ainda a realização de entrevistas em agências do Sicred, do Sicoob, da Uniprime e da Bolsa de Cereais e Mercadorias de Londrina (2016) como recurso à compreensão das atividades realizadas pelas unidades de atendimentos, das escolhas locacionais para agências, das articulações desse sistema com a financeirização da economia vinculada à comercialização de commodities, entre outros.

recorte temporal adotado se apoia em: a) facilidade de obtenção de dados junto ao $\mathrm{BCB}$, com acervo disponível no próprio site do banco; b) no fato de que as principais mudanças que ocorreram nos bancos públicos se realizam a partir de 1997, com o Programa de Incentivo à Redução do Setor Público Estadual na Atividade Bancária (Proes), enquanto os bancos privados foram afetados pelo Programa de Estímulo à Reestruturação e ao Fortalecimento do Sistema Financeiro Nacional (Proer), implantado em 1995. Dessa forma, o recorte adotado a partir de 1997 possibilitou identificar os efeitos perversos da implantação de políticas macroeconômicas neoliberais na economia brasileira, como a privatização do sistema bancário 
nacional público e venda ou fusões de bancos privados nacionais ao capital internacional; possibilitou ainda a identificação da expansão do sistema cooperativo de crédito como estratégia fundamental para ocupar áreas deixadas de serem atendidas pelo sistema oficial de crédito. Ao mesmo tempo, bibliografias permitiram a compreensão de como se apresentava o sistema bancário anterior a 1997, possibilitando identificar a evolução do mesmo.

○ texto está organizado em três partes, além da introdução e considerações finais. Na primeira se apresentam alguns apontamentos sobre a compreensão de redes geográficas, porque, rede urbana e rede bancária são geográficas, das quais a primeira é a mais complexa, permitindo até certo ponto, o funcionamento da rede bancária. Apresenta-se ainda uma breve caracterização da rede urbana do Norte do Paraná. Na segunda parte se apresenta a evolução da rede bancária de 1997 a fevereiro de 2016, com números das agências bancárias, dos postos de atendimento eletrônico, de atendimento avançado, posto de câmbio permanente e unidades de atendimento do sistema cooperativo de crédito na rede urbana do Norte do Paraná. Acrescenta-se ainda a evolução do sistema por bancos. Na terceira parte são discutidas razões da evolução na rede urbana, chamando-se a atenção para as fortes transformações que afetaram a dinâmica bancária desde meados dos anos 1990, bem como apontamentos sobre a dinâmica econômica nacional no período citado. Particular atenção foi dada ao período 2003-2013, no qual a oferta de crédito e alterações em normas legais permitiu avanço do processo de financeirização na rede urbana, articulada fundamentalmente à comercialização de commodities.

\section{Redes geográficas: urbana e bancária}

A rede urbana pode ser compreendida inicialmente "[...] como um conjunto de centros funcionalmente articulado" (Corrêa, 1989, p. 8), cuja conceituação está apoiada em longa tradição em seu estudo e vasta bibliografia. Se inicialmente a conceituação e os estudos sobre redes apoiavam-se nos princípios christallerianos (Christaller, 1966), há pelo menos três décadas na geografia brasileira as análises passaram a ser realizadas com a inclusão de outros referenciais teóricos e metodológicos. Isso não significa que a teoria sobre as localidades centrais deva ser desconsiderada, mas seus referenciais não são suficientes para o entendimento de uma rede urbana. Críticas e avanços sobre a teoria podem ser verificados em Corrêa (1982), entre outros.

Por isso, a análise aqui é pautada em uma compreensão da rede urbana como conjunto de centros funcionalmente articulado, como uma dimensão socioespacial da sociedade ou estrutura territorial, por meio da qual se realizam processos de criação, apropriação e circulação do valor excedente (Corrêa, 1989). Em outros termos, a rede urbana pode ser considerada "[...] um produto social, historicamente contextualizado, cujo papel crucial é o de, através de interações sociais espacializadas, articular toda a sociedade numa dada porção do espaço, garantindo a sua existência e reprodução" (Corrêa, 1997, p. 93).

Neste sentido, entende-se que a "[...] rede urbana constitui-se simultaneamente em um reflexo da divisão territorial do trabalho e numa condição para a divisão territorial do trabalho" (Corrêa, 1989, p. 48), como caminho profícuo para compreender como esta categoria se constitui em um dos motores da vida social e da diferenciação espacial (Santos, 1996, p. 104). Reflexo porque traduz arranjos da ocupação do território, os elementos relativos à produção, relações sociais, renda, distribuição, sua evolução, entre outros. A rede coloca-se como condição porque 
estabelece os pontos focais da vida de relações, vias de tráfego, os fluxos materiais e imateriais, para criação e transformação desigual e constante de atividades e cidades. São nas cidades de uma rede urbana, articuladas por sistemas técnicos de diferentes temporalidades, que se realizam fluxos materiais e imateriais internamente como externamente à rede e se têm condições para a produção, distribuição, circulação e consumo (Corrêa, 1989).

Há importante bibliografia geográfica brasileira sobre o sistema bancário que discutem diferentes aspectos do mesmo: seu papel e importância no desenvolvimento nacional; mudanças espaciais da rede bancária; principais redes bancárias e suas transformações em diferentes momentos temporais; as normas legais de suas regulações; os efeitos da globalização no sistema bancário; avanços técnicos incorporados pelo sistema bancário; entre outras. No entanto, é preciso compreender que as redes urbana e bancária são redes geográficas e, como tais, apresentam inúmeras articulações a serem discutidas. A começar pelo fato de que rede bancária é uma rede geográfica presente em uma rede urbana, a mais complexa de todas as redes geográficas, porque nela se fazem presentes uma numerosa quantidade de outras redes, materiais ou imateriais. A rede urbana traduz a diversidade e complexidade de outras redes geográficas nela presentes.

Uma rede geográfica deve ser entendida como "[...] conjunto de localizações humanas articuladas entre si por meio de vias e fluxos" (Corrêa, 2012, p. 200), como uma cooperativa e as ligações entre suas unidades industriais, os produtores rurais e as fazendas; ou entre uma corporação, cujas unidades industriais e prestadoras de serviços estão conectadas por fluxos materiais e imateriais, tanto na escala de um país como mundialmente.

Ao mesmo tempo, o que a torna geográfica são as localizações qualificadas e as interações espaciais, inserindo-se no complexo processo de organização espacial socialmente engendrado (Corrêa, 2012). Santos (1996), ao discutir redes, chama a atenção para duas matrizes: a primeira é a forma, a realidade material da rede; a outra é constituída pelo dado social. Na primeira, a técnica é fundamental gerando materialidades na forma de infraestrutura, que possibilita o transporte de matéria, energia e informação. Por isso mesmo, tem temporalidades distintas que se articulam, excluem ou sobrepõem-se às demais, mas caracterizadas pelos pontos de acesso. No caso da segunda, a rede é "[...] social e política, pelas pessoas, mensagens, valores que a frequentam. Sem isso, e a despeito da materialidade com que se impõe aos nossos sentidos, a rede é, na verdade, uma mera abstração" (Santos, 1996, p. 209). Desta maneira, as redes estão articuladas a certos propósitos, relações sociais de produção e reprodução, mais o dado político e normativo.

As redes geográficas são formas de integração e exclusão e de poder; poder no sentido de ter sob seu controle uma vasta área, e a partir de decisões oriundas das mais diferentes localizações, afeta diretamente a mesma. A rede bancária não está desconectada do poder e da dimensão espacial, muito pelo contrário. Uma rede bancária utiliza e impõe a necessidade de outras redes geográficas como a energética, a de comunicação por satélite, fibra óptica, telefônica etc. E as análises de Santos (1996) sobre as técnicas são fundamentais porque permitem entender diversos aspectos dos fixos e dos fluxos. Pode-se acessar o banco em qualquer lugar que tenha energia, internet e um telefone celular; mas só depois que a conta corrente/poupança for aberta em uma unidade bancária, de modo a garantir a veracidade das informações do cliente, de sua assinatura cumprindo exigências normativas. E o controle sobre quem pode ou não ter acesso a esse serviço é uma forma de poder. 
A partir das perspectivas anteriormente colocadas, importa entender alguns aspectos de uma rede urbana regional, como caminho para melhor articular com a rede bancária e outras redes geográficas. Trata-se da rede urbana do Norte do Paraná, conforme Mapa 1. Sobre a estruturação, há diversidade de bibliografia como em Fresca (2002, 2004), Endlich (1996), Asalin (2015) etc., além de artigos que discutem hierarquias urbanas, área de atuação e interações espaciais a partir de diferentes atividades e cidades.

Trata-se de uma rede urbana que teve sua estruturação a partir do final do século XIX em sua porção leste, mas cuja ocupação foi rarefeita. Entre as décadas de 1930 e 1960 ocorreu efetiva ocupação do território e estruturação da rede urbana do Norte do Paraná, baseada em relações sociais que combinavam assalariamento e colonato, conformando uma formação econômica, social e espacial de pequena produção mercantil, baseada em trabalho familiar em pequenas propriedades rurais, produção voltada para o mercado interno (gêneros alimentícios e matérias-primas) e internacional (café).

Do ponto de vista das cidades, estas foram criadas predominantemente sob a forma de loteamentos urbanos, como condição sine qua non para que as atividades produtivas agropecuárias se realizassem: como a coleta, transformação, comercialização e transporte; além da oferta de bens e serviços à população rural e urbana. Do desempenho destas funções emergia uma diferenciação hierárquica entre as cidades muito mais pautada na quantidade do que na qualidade das funções desempenhadas. Uma rede urbana do tipo christalleriano, isto é, alguns dos princípios da teoria das localidades centrais se fizeram presentes na estruturação da rede.

\section{Mapa 1 - Rede urbana do Norte do Paraná, 1993}

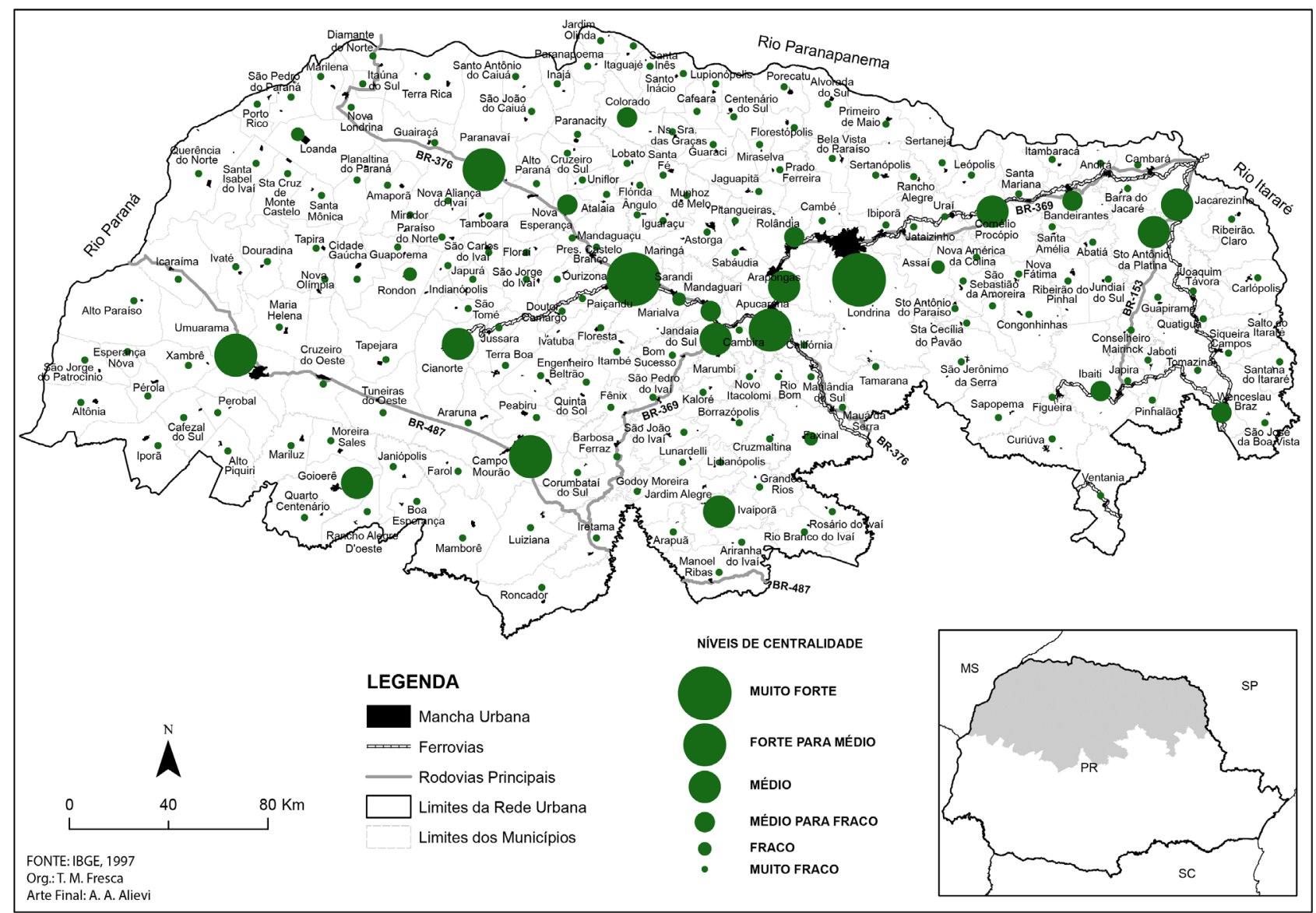


Em seu desenvolvimento, essa rede urbana passou por grandes transformações econômicas, populacionais, de infraestrutura, de produção industrial, agropecuárias etc. entre os anos 1960-1970. Resulta do conjunto de transformações o fato de ter ocorrido uma complexidade da rede, vinculada à intensificação dos processos de produção, circulação, distribuição e consumo. Na medida em que processos gerais foram incidindo na rede urbana, emergiu uma heterogeneidade que antes não estava presente e na qual o que mais se ressalta é a continuidade da diferenciação e redefinição dos lugares: complexos agroindustriais; a produção industrial foi ampliada, gerando inclusive cidades com especialização em certas produções industriais; inclui ainda outra dinâmica populacional, em que se destaca o esvaziamento demográfico do campo e aumento da taxa de urbanização para os municípios da rede; entre outros. Simultaneamente a outra densidade produtiva instaurada na rede urbana, ocorreu melhoria geral da circulação como etapa necessária entre produção, distribuição e consumo. As estruturas para a circulação passaram por avanços permitindo maior fluidez e flexibilidade à circulação de pessoas, mercadorias, capital, ideias, valores. Possibilitou ampliação da inserção de cidades em diversas redes urbanas e em outras redes.

Outra complexidade funcional dos centros urbanos se faz presente, traduzida em enormes diferenciações entre as cidades vinculadas às suas inserções na divisão territorial do trabalho. Assim, a rede urbana do Norte do Paraná apresenta-se complexa, com todos os níveis de centralidade, a exceção do metropolitano, mas inclui o nível submetropolitano. Aqui se utilizou o Regic de 1993 (IBGE, 2000) e não o de 2007 (IBGE, 2008), cuja razão básica se vincula ao fato desse último trabalho articular rede urbana com a discussão sobre gestão do território, utilizando como elemento a gestão federal e empresarial (Oliveira, 2011). Não se critica este procedimento, mas, no momento de efetuar a classificação das cidades a partir dos critérios e variáveis estabelecidos, o peso recaiu sobre os serviços públicos federais e gestão empresarial. Por isso, utilizou-se aqui o Regic de 1993 (IBGE, 2000), porque teoricamente incorpora os avanços à teoria das localidades centrais e demonstra a enorme complexidade da rede urbana nacional.

\section{Evolução da rede bancária na rede urbana do Norte do Paraná}

Com relação ao sistema bancário, o Mapa 2 apresenta o número de agências bancárias no ano de 1997 nas cidades da rede urbana. $\bigcirc$ maior número dessas estava em Londrina com 56, seguida por Maringá com 39 agências, seguida por Paranavaí, Umuarama, Cianorte, Apucarana e Arapongas. Verifica-se maior concentração nas cidades localizadas ao longo das principais vias de transporte, que não é determinante e nem se constitui uma estrutura explicativa. Há forte correlação entre o número de agências com o nível de centralidade das cidades da rede urbana. Quanto maior a cidade em termos populacionais e correlatamente maior diversidade de atividades urbanas, maior o número de agências. Isso não significa a reprodução dos princípios christallerianos tal qual formulados, mas há evidências dessa correlação. Fato importante nessa data é que todas as cidades têm pelo menos uma agência bancária; o processo de exclusão dessas em várias cidades só vai ocorrer em futuro próximo. Observa-se que as maiores concentrações de cidades com apenas uma agência está na porção extremo leste, ao sul da BR-369; no extremo noroeste; ao sul de Londrina e Maringá e nas margens com o rio Paranapanema, ao norte de Londrina. 
Em 1997, os bancos presentes na rede urbana eram predominantemente os nacionais. Eram 548 agências assim distribuídas em termos de bancos: 169 do Banestado; 155 do Bradesco; 84 do Banco do Brasil; 77 do HSBC (ex-Bamerindus); 35 da Caixa Econômica Federal; 11 do Itaú; 08 do Unibanco e Santander; 09 do Real e Mercantil de São Paulo; mas havia ainda agências do Banespa, Banco Alvorada, entre outros. Os bancos públicos e privados nacionais ainda eram os predominantes, pois os efeitos das grandes transformações bancárias nacionais ainda não haviam sido efetivamente implantados. Mas, as normas legais para essas transformações foram implantadas em 1995, com o PROER, e em 1997 com o PROES, que serão discutidos adiante.

\section{Mapa 2 - Agências bancárias na rede urbana do Norte do Paraná, 1997}

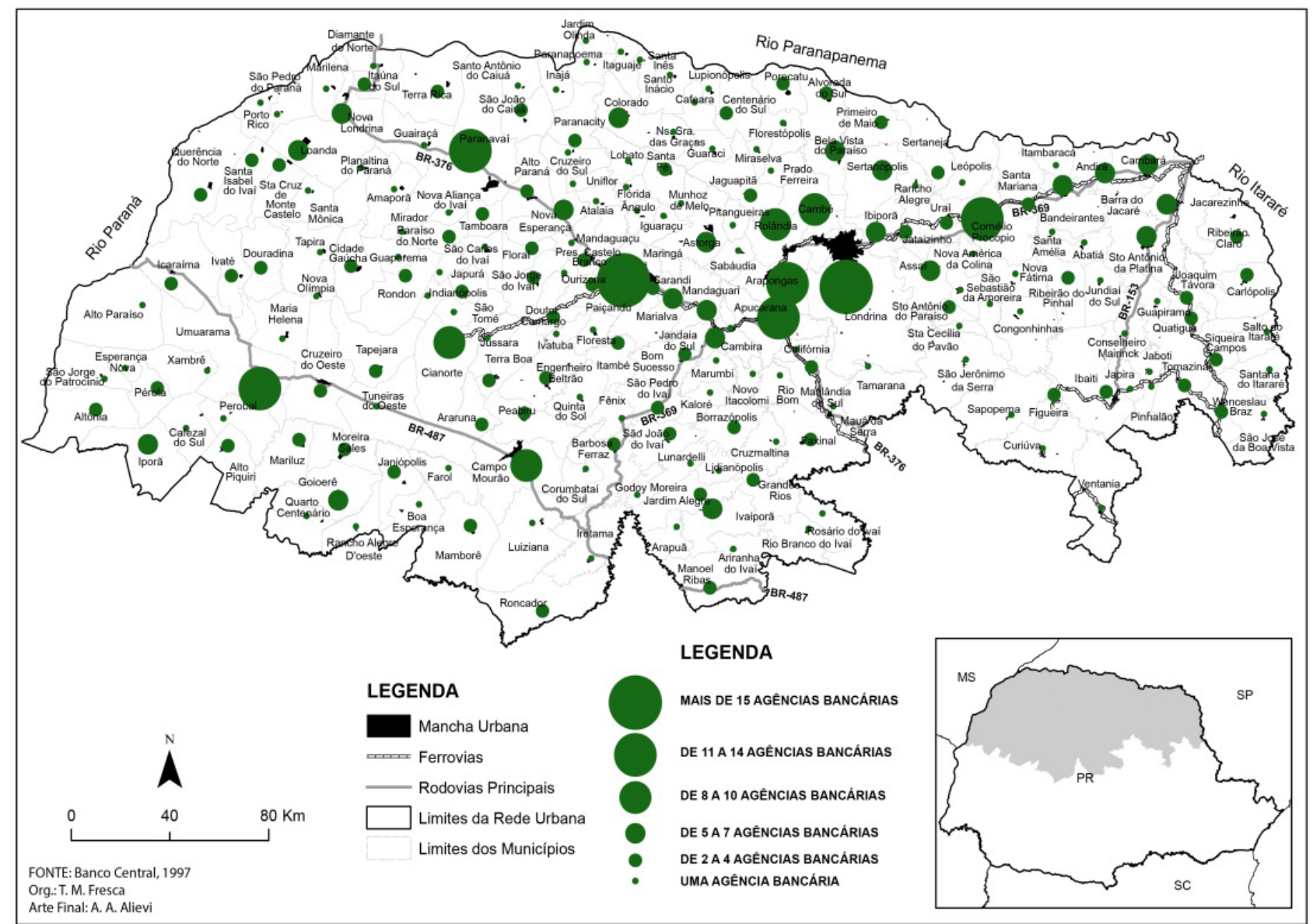

O Mapa 3 com as agências bancárias em 2007 e unidades bancárias em 2006, apresenta situação bastante distinta em relação ao anterior. Do ponto de vista da distribuição das agências em 2006, as maiores concentrações estavam em Londrina com 68, Maringá com 44, Apucarana, Arapongas e Umuarama com 10 cada, Campo Mourão com 08 e Paranavaí com 07. Verifica-se ainda que 36 municípios não contavam com agências, estando localizados predominantemente na porção noroeste, porção extremo leste e sul da rede urbana. Em linhas gerais, correspondem em parte àqueles que só apresentavam uma agência em 1997. Os municípios sem presença de agências em suas sedes urbanas são aqueles que apresentam 
centralidade muito fraca, os centros locais. No entanto, a maioria dessas cidades não estava desassistida de atendimento bancário, realizado por intermédio de Postos de Atendimento Bancário (PAB), Posto de Atendimento Eletrônico (PAE), Posto Avançado de Atendimento (PAA), Posto Bancário de Arrecadação e Pagamento (PAP). A data de 2007 para essas unidades e 2006 para agências se justifica em razão das dificuldades de obtenção de ambos os dados para a mesma data junto ao BCB e bibliografia disponível. É necessário esclarecer que os postos de atendimentos bancários presentes no mapa correspondem à somatória de todos os tipos presentes na rede urbana dos bancos múltiplos.

\section{Mapa 3 - Agências e postos de atendimento bancário na rede urbana do Norte do Paraná, 2006-2007}

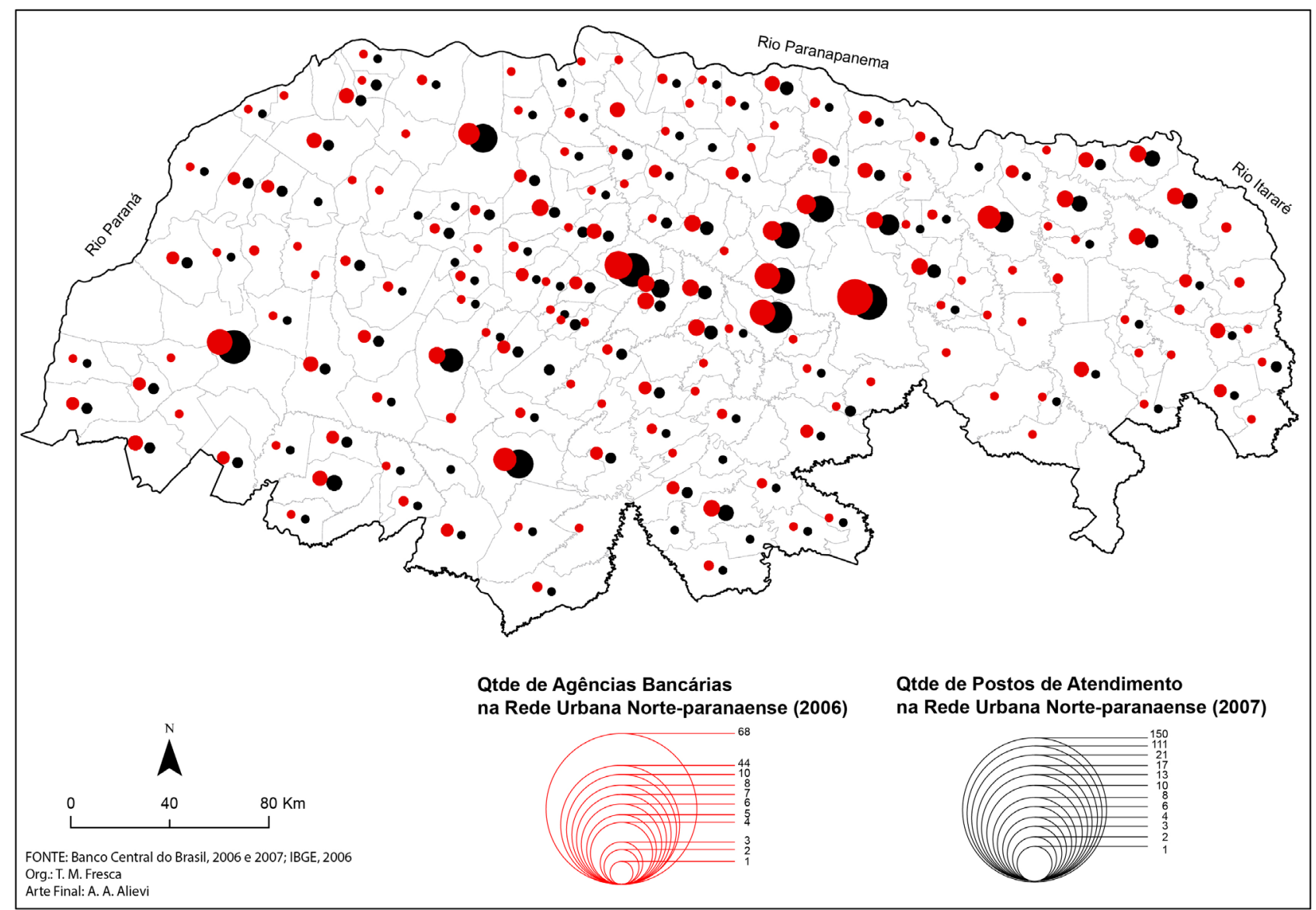

Os postos de atendimento somavam 588 e estavam assim distribuídos por tipos: 06 PAA, dos quais 03 eram do Bradesco, 01 do Itaú, 01 do HSBC e 01 Unibanco; 91 PAB, dos quais 02 do Banco ABN ANRO Real, 10 do Bradesco, 20 do Banco do Brasil, 16 do Itaú, 03 do Santander, 28 da CEF, 07 do HSBC e 05 do Unibanco. Os postos de atendimento eletrônico somavam 489, representando 83,16\% do total, com destaque para o Banco do Brasil com 206, Bradesco com 164, Itaú com 50, CEF com 21 e 09 do Banco ABN ANRO Real.

Mas, algumas cidades, que não contavam com nenhuma dessas unidades, sendo atendidas por banco postal, instituído no ano de 2000, como em Barra do Jacaré, Nova América da Colina, entre outros. Denota-se a exclusão de acesso deste serviço tornado fundamental 
à vida cotidiana e à produção propriamente dita. Essas cidades sem agências eram atendidas pelo Bradesco, por meio do banco postal, em parceria com os Correios: realizavam abertura de conta corrente, empréstimos, cartão de crédito, pagamento de benefícios do INSS, recebimento de contas, títulos, taxas e contribuições.

Com relação aos bancos presentes na rede urbana, o predomínio permaneceu com os públicos e privados nacionais, mas foi ampliada a participação dos bancos estrangeiros: 116 agências do Banco do Brasil, 133 do Itaú, 75 do Bradesco, 45 da CEF; entre os internacionais os destaques ficaram por conta do HSBC, com 52 agências, além de 21 do ABN ANRO Real; os públicos representaram 41,8\% do total de agências em 2006.

Os dados apresentados se articulam diretamente com as transformações bancárias que foram ampliadas a partir de meados dos anos 1990, em direção à reestruturação do sistema bancário/financeiro. A implantação do Plano Real em 1994, do Proer em 1995 e o Proes em 1997, além de outras ações implantadas pelo Banco Central entre 1994-2002, como foi o caso do Sistema Financeiro Imobiliário (SFI) em 1997, afetaram de modo substancial a rede bancária. Esses programas foram implantados em direção a facilitar o processo de privatização dos bancos públicos estaduais e aquisição de bancos privados nacionais pelo capital internacional. Dias, Lenzi, Corigliano (2011) informam que, entre 1995 e 1998, 14 bancos comerciais e múltiplos foram autorizados a se instalarem no país, mediante aquisição do controle acionário de bancos nacionais; entre 1994 e 2005 ocorreu uma redução de 244 para 160 bancos comerciais e múltiplos no Brasil. Assim, privatização e concentração induzida do sistema bancário privado (Contel, 2007) são faces do processo de imposição da racionalidade neoliberal.

A partir destes processos, ocorreu uma reorganização espacial das redes bancárias no Brasil e na rede urbana do Norte do Paraná. Essas redes reduziram o número de agências, principalmente em cidades com pequena população e de fraco nível de centralidade, articulado à lógica da maximização dos lucros. Quando se diz que as pequenas cidades foram as mais afetadas, significa que é uma tendência e não regra geral. Assim, concentração (dos bancos) e exclusão (de municípios e cidades sem agências) estão articuladas.

Por outro lado, foi ampliado o acesso ao serviço bancário através de postos bancários, caixas eletrônicos, banco postal, correspondente bancário etc., alterando a rede em direção ao que Contel (2007) denominou hipercapilaridade das finanças, isto é, a capacidade de ampliação de acesso a bancos por outros sistemas referidos anteriormente. Tanto assim que, na rede urbana em 1997, havia 548 agências e em 2006 era de 504, número reduzido ainda mais em 2007 com 482 agências. Vale notar que a ampliação dessas modalidades de atendimento bancário (caixa eletrônico, banco postal, correspondente bancário) se correlaciona com a evolução e ampliação das redes geográficas de comunicação e informação.

O Mapa 4 apresenta o número de agências bancárias, postos de atendimento, conforme já explicitado, e unidades de atendimento do Banco Cooperativo Sicredi e do Sistema de Cooperativas de Crédito do Brasil (Sicoob) na rede urbana do Norte do Paraná, no ano de 2014. O mapa permite ver que, o maior número de agências e postos de atendimento continuam nas maiores cidades, principalmente na porção central da rede urbana; os postos de atendimento estão fracamente presentes na porção sudeste e noroeste da rede urbana, ratificando áreas anteriormente citadas; que a maior concentração de número de agências continua nas maiores cidades da rede. 


\section{Mapa 4 - Agências, postos de atendimento bancário e unidades de atendimento na rede urbana do Norte do Paraná, 2014 e 2016}

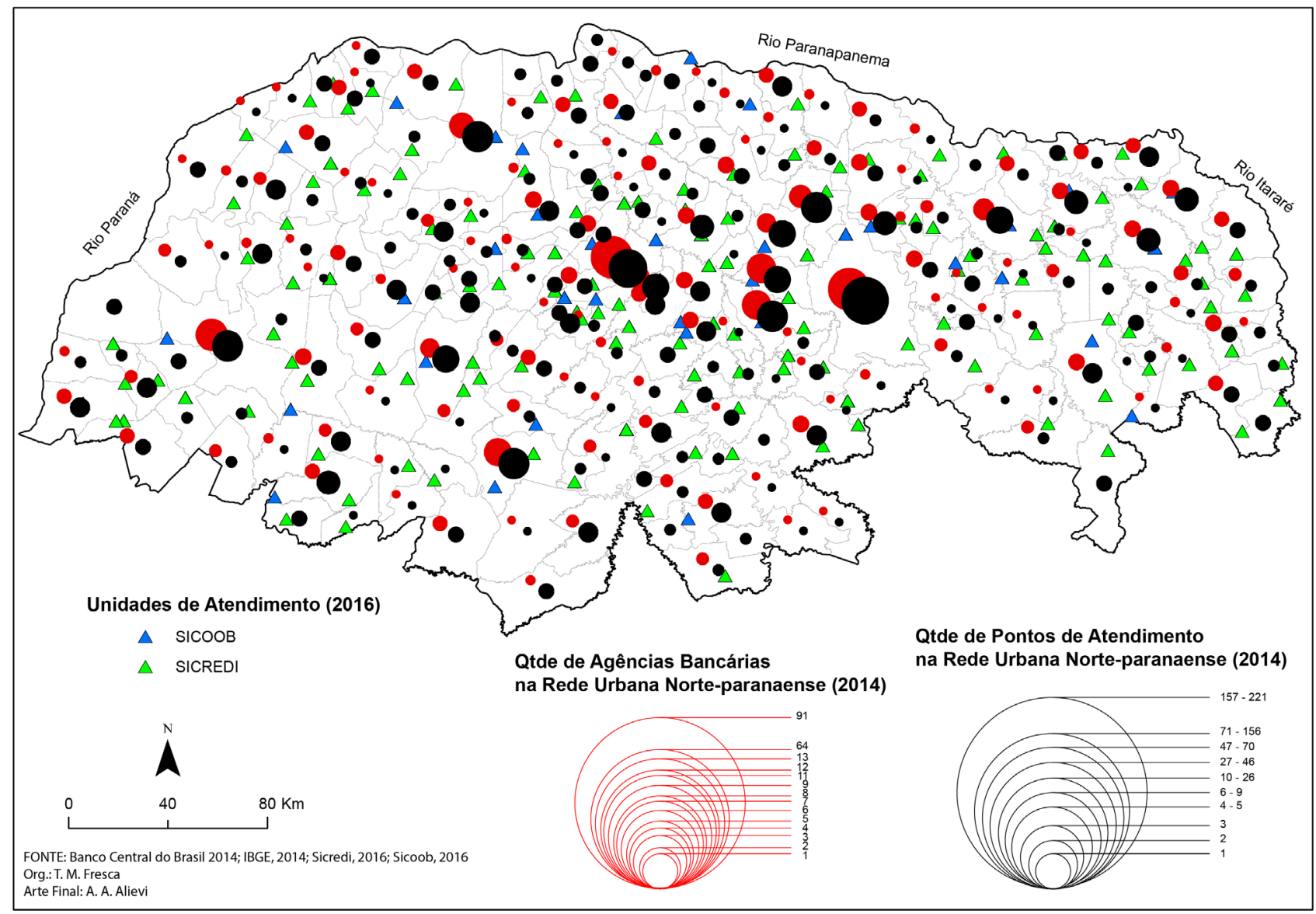

Se em 2006 havia 36 municípios sem agências, em 2014 esse número foi elevado para 61 e desses, somente dois não tinham nenhum posto bancário, apenas correspondestes postais e banco postal. A localização dos municípios sem agências segue em linhas gerais as mesmas anteriormente citadas. Em 2014, as 571 agências estavam assim distribuídas: 147 do Itaú-Unibanco; 128 do Banco do Brasil; 123 do Bradesco; 73 da CEF; 48 do HSBC; 39 do Santander; com 02 agências cada estava o Mercantil do Brasil, Safra, Sofisa, Triângulo; com 01 agência cada o Citibank, Daycoval, Industrial e Comercial, Novo Banco Continental. Os bancos públicos reduziram sua participação no total de agências para $35,2 \%$.

Com relação aos postos de atendimento, somavam 1063 assim distribuídos: 81 era posto de atendimento avançado; 125 de atendimento bancário; 825 caixas eletrônicos e 32 de câmbio. Do total, 381 eram do Bradesco, 272 do Banco do Brasil, 262 da CEF, 97 do Itaú-Unibanco, 17 do HSBC, 04 da Confidence Corretora, 03 da OM Distribuidora de Títulos, 01 da AGK Câmbio, 01 do Original e 01 do Rendimento. Do total dos postos de câmbio, 81,25\% pertenciam ao Itaú-Unibanco. Aqui há maior participação dos bancos públicos, representando em 50,23\% em 2014. Até o momento, os dados permitem notar claramente a continuidade do aumento de agências e postos de atendimentos bancários na rede urbana, embora para as agências a taxa de crescimento foi menor (18,4\% entre 2007-2014) comparativo aos postos 
cuja expansão foi de 80,7\% entre 2007-2014. Há que se considerar ainda que os dados para a rede urbana foram bastante oscilantes entre 2006 e 2014, conforme Quadro 1. Verifica-se que os índices de expansão das agências para o Brasil, estado do Paraná e Rede Urbana não são similares, embora a tendência mais geral se manifeste igualmente.

Assim, entre 1997 a 2007 ocorreu uma redução do número de agências na rede urbana, contrariando a tendência nacional que foi de expansão, embora com taxas baixas. Em 2010, o número de agências foi maior que o verificado para 2007, e prosseguiu em expansão até fevereiro de 2016, quando atingiu número maior que o verificado em 1997, mas um crescimento de apenas 0,9\%. Entre 2014 e 2016, o que se verificou foi redução dessas para o Brasil, estado do Paraná e rede urbana; mas vale notar que 2014 foi o ano com maior número de agências na rede urbana desde 1997. Distinta foi a evolução de postos de atendimento entre 2007 e 2014, cujo crescimento foi positivo; em 2016 apresentou redução em termos absolutos.

\section{Quadro 1 - Evolução do número de agências e postos bancários no Brasil, Paraná e rede urbana do Norte do Paraná: 1997 a fevereiro de 2016}

\begin{tabular}{l|r|r|r|r|r|r}
\cline { 2 - 7 } & \multicolumn{2}{c|}{ Brasil } & \multicolumn{2}{c|}{ Paraná } & \multicolumn{2}{c}{ rede urbana norte Paraná } \\
\cline { 2 - 8 } & agências & postos & agências & postos & agências & \multicolumn{2}{c}{ postos } \\
\hline $\mathbf{1 9 9 7}$ & 15.972 & - & 1.251 & - & 548 & - \\
\hline 2000 & 16.396 & - & 1.243 & - & 513 & - \\
\hline 2002 & 17.049 & - & 1.267 & - & 525 & - \\
\hline $\mathbf{2 0 0 4}$ & 17.203 & - & 1.243 & - & 516 & - \\
\hline $\mathbf{2 0 0 5}$ & 17.515 & - & 1.264 & - & 503 & 588 \\
\hline $\mathbf{2 0 0 6}$ & 18.029 & - & 1.283 & - & 504 & 791 \\
\hline $\mathbf{2 0 0 7}$ & 18.456 & 38.365 & 1.278 & 2.277 & 482 & 1.063 \\
\hline $\mathbf{2 0 1 0}$ & 19.488 & 44.346 & 1.337 & 2.738 & 493 & 913 \\
\hline $\mathbf{2 0 1 4}$ & 23.127 & 50.954 & 1.594 & 3.182 & 571 & 53 \\
\hline $\mathrm{fev} / 16$ & 22.967 & 44.968 & 1.564 & 2.728 & 553 & - \\
\hline
\end{tabular}

fonte: BCB (2016b).

Ampliação de postos de atendimentos em suas diversas modalidades corresponde a uma estratégia de redução de custos, na medida em que o número de funcionários é muito menor e não existente no caso dos caixas eletrônicos. A isso se acrescenta ainda a facilidade de solução de questões diversas por intermédio da internet, pois os bancos implantaram sistemas de comunicação de atendimento aos clientes; foi ampliado ainda o uso de telefone celular, que permitiu o acesso aos bancos mediante uso da internet para várias transações. Os postos de câmbio permanente tiveram expansão entre 2006-2014, totalizando na última data 32 unidades localizadas predominantemente nas maiores cidades; em 2007 não havia nenhum na rede urbana. Essa tipologia se vincula à intensificação do mercado de câmbio, principalmente pela compra de dólares por pessoas físicas e outras atividades. 
Em outros termos, evidenciam-se estratégias de expansão através de caixas eletrônicos, que reduzem utilização de mão de obra, custos com imóveis, entre outros, a utilizarem inovações de forma mais acentuada. Por outro lado, expressam ainda a expansão quantitativa do acesso a caixas eletrônicos, mas seletivamente do ponto de vista espacial; a expansão dos postos de atendimento avançados reflete estratégias de redução de custos também de mão de obra e locação de imóveis predominantemente, enquanto os postos de câmbio vinculam-se à estratégia de atendimento de demandas nas maiores cidades.

Em fevereiro de 2016, a rede urbana contava com 553 agências bancárias, das quais: 114 do Bradesco, 127 do Banco do Brasil, 141 do Itaú-Unibanco, 73 da CEF, 38 do Santander, 47 do HSBC, enquanto bancos como Triângulo, Sofisa, Citibank, Daycoval, Novo Banco Continental contavam com 01 agência e o Safra com 02; destaque para 01 agência do China Construction Bank em Londrina (que adquiriu em 2014 o Bicbanco no Brasil). Os bancos públicos ampliaram sua participação na rede urbana, representando 36,16\%.

Os postos de atendimento bancário em fevereiro de 2016 totalizavam 913, dos quais 89 eram postos de atendimento avançado; 121 eram postos de atendimento bancário; 672 caixas eletrônicos e 31 postos de câmbio permanente. Do total de postos, 349 eram do Bradesco (dos quais 265 eram caixas eletrônicos), 242 do Banco do Brasil (dos quais 204 eram caixas eletrônicos), 213 da CEF (167 caixas eletrônicos), 59 do Itaú-Unibanco, 20 do Santander e 08 do HSBC.

Do ponto de vista da tipologia do sistema financeiro, é necessário retornar ao Mapa 4 para discutir as unidades de atendimento do Sistema de Crédito Cooperativo (Sicredi) e do Sicoob. A primeira funciona a partir de 95 cooperativas de crédito afiliadas, quatro centrais regionais - acionistas da Sicredi Participações S.A. - , uma confederação, uma Fundação e o Banco Cooperativo Sicredi e suas empresas controladas. Convém apontar que o Sicredi foi o primeiro banco cooperativo privado criado no Brasil em 1995, atuando em 2016 em 11 estados brasileiros, totalizando cerca de 1.400 unidades de atendimento (Portal do Cooperativismo Financeiro, 2016c).

A segunda envolve também cooperativas singulares no total de 487; 15 cooperativas centrais; uma confederação; o Banco Cooperativo do Brasil S.A. (Bancoob); uma bandeira e processadora de cartões denominada Cabal Brasil; a Bancoob Distribuidora de Títulos e Valores Mobiliários Ltda (Bancoob DTVM); uma empresa que atua na administração e gestão de recursos do Sicoob e de terceiros e a Sicoob Previ que atua com previdência privada. Atua em 23 estados brasileiros, atendendo cerca de 2,7 milhões de cooperados, com maior concentração nos estados de São Paulo, Minas Gerais e Santa Catarina. De acordo com o Portal do Cooperativismo Financeiro (2016b), em torno de 50\% de seus associados residem em municípios com menos de 50 mil habitantes, estabelecendo uma estratégia para localização de suas unidades de atendimento, ou seja, as agências bancárias.

Tendo em vista que o sistema cooperativo têm normas específicas, conforme regulamentações do Banco Central há algumas diferenças em relação aos bancos comerciais. A primeira delas é o fato de que seus dados não constam nos relatórios bancários por municípios junto ao Banco Central; seus dados aparecem apenas como um banco e a cidade sede; não aparecem as unidades de atendimento desse sistema, já que articulados às cooperativas afiliadas. Dessa forma, essa tipologia de sistema bancário nem sempre é levada em conta nas análises sobre redes bancárias, deixando-se de considerar que esse representou 2,88\% no total de ativos do mercado 
financeiro brasileiro em dezembro de 2015 e sexta posição nacional (Portal do Cooperativismo Financeiro, 2016a). Nesse sistema cooperativo, estão inclusos, além dos citados, a Unicred, Cecred, Confesol, Uniprime e Cecrers. Individualmente, o Banco Sicredi ocupou o 40 lugar entre os maiores bancos em 2015 em ativos totais, enquanto o Sicoob ocupou a 44' posição.

Em realidade são sistemas criados nos anos 1990, cujas principais regulamentações federais ocorreram em 2009 e 2015, a permitirem a autorização para funcionamento, alterações estatutárias e, acima de tudo, autorização para financiamentos diversos. A partir de então as cooperativas de créditos passaram a expandir suas atuações em momento em que os bancos públicos estaduais eram privatizados, em que os principais bancos privados reduziam agências e postos de atendimento. Ocuparam, portanto, uma brecha deixada no mercado bancário brasileiro e no Norte do Paraná, a expandirem suas unidades de atendimentos em cidades menores, cujas centralidades são muito fracas, em área de forte presença do cooperativismo agropecuário, implantado desde os anos 1950.

Essa é uma especificidade da rede urbana, não exclusivamente, porque apresentam relativo elevado número de unidades de atendimento, conforme pode ser verificado no Mapa 4. $\bigcirc$ Sicredi tinha em fevereiro de 2016, 141 unidades, mais as sedes das cooperativas afiliadas; o Sicoob apresentava 40 unidades, totalizando 181 agências desse sistema cooperativo de crédito. Considerando que as unidades de atendimento são agências bancárias, o total dessas na rede urbana do Norte do Paraná atingiu na data referida acima 752 agências. E aqui não se está considerando o sistema Uniprime, outro sistema cooperativo de crédito voltado principalmente a profissionais liberais diversos, que só no Norte do Paraná contava com 14 agências.

Do ponto de vista de sua distribuição na rede urbana, verifica-se que as unidades do Sicredi estão dispersamente localizadas, inclusive nas pequenas cidades, colocando-as como nichos de mercados e estratégia espacial para sua atuação. No caso do Sicoob, a maior concentração está nas cidades onde há também maior número de agências bancárias, denotando diversidade de estratégias espaciais de atuação.

\section{A financeirização da economia e consumo familiar}

Como entender esses elementos aqui colocados? A redução do número de agências de bancos múltiplos e ampliação daquelas vinculadas ao sistema cooperativo de crédito devem ser tomadas como fatores de dinamismo na rede urbana. Isso porque essas agências tiveram importante expansão após 2003. Em fevereiro de 2016 alcançaram 181 unidades, denotando concorrência entre sistema cooperativo com bancos múltiplos. Eis outra face da topologia do sistema financeiro. A ampliação do número de cidades sem agências, com ampliação de postos de atendimento bancários, particularmente caixas eletrônicos e postos avançados de atendimento, demonstra aspectos da organização espacial das redes bancárias e o processo de exclusão e, ao mesmo tempo, de acesso ao sistema por outros mecanismos.

Dos dados apresentados é necessário entender aspectos do sistema de crédito nacional, especialmente no período entre 2003-2013, de forte dinâmica econômica virtuosa. Destacam-se aqui dois caminhos dessa expansão: o crédito rural tendo em vista o fato do estado do Paraná ser grande produtor de commodities (soja, frango, açúcar etc.); e o crédito vinculado às familias, com forte redução de taxas de juros. 


\section{Quadro 2 - Valores do Pronaf no Brasil e no estado do Paraná: 1999-2012 (R\$)}

\begin{tabular}{c|r|c|c}
\cline { 2 - 4 } \multicolumn{2}{c|}{ Brasil } & Paraná & \% do PR sobre BR \\
\hline 1999 & 1.777 bilhões & 267 milhões & 15,01 \\
\hline 2003 & 3.158 bilhões & 401 milhões & 12,69 \\
\hline 2006 & 7.166 bilhões & 778 milhões & 10,85 \\
\hline 2012 & 16.359 bilhões & 2.389 bilhões & 14,60 \\
\hline
\end{tabular}

fonte: BCB (2016a).

\section{Quadro 3 - Utilização dos financiamentos obtidos por cooperativas do Paraná: 1999-2012 (\%)}

\begin{tabular}{r|r|r|r}
\cline { 2 - 4 } & custeio & investimentos & comercialização \\
\hline 1999 & 40,28 & 23,77 & 35,08 \\
\hline 2003 & 38,05 & 32,9 & 31,09 \\
\hline 2006 & 30,5 & 26,2 & 19,89 \\
\hline 2012 & 35 & 37,52 & 17,99 \\
\hline
\end{tabular}

fonte: BCB (2016a).

Primeiro é o crédito rural com expansão muito positiva desde 2003, conforme Quadros 2 e 3. Quanto aos valores do Pronaf, vale notar a elevada participação do Paraná no total desse crédito no país. Como esse Programa de Fortalecimento da Agricultura Familiar apresenta diversas modalidades, mas destina-se, sobretudo, a pequenos produtores rurais, o estado teve a segunda maior participação do país em 2012, só perdendo para o Mato Grosso do Sul em termos de rendimentos. Chama a atenção o fato de que do total obtido no Paraná em 2012, 37\% destinaram-se a investimentos; superior que os utilizados para custeio e comercialização.

Quanto à utilização dos financiamentos obtidos por cooperativas, também se destaca a relativa permanência dos índices para custeio, redução para comercialização e ampliação para investimentos. Há ainda alguns dados sobre outras formas de obtenção de financiamentos a serem utilizados na agropecuária, para investimentos, custeio e comercialização. Trata-se do sistema financeiro através da Cédula do Produto Rural, da Letra de Crédito do Agronegócio e do Certificado de Direitos Creditórios do Agronegócio. Embora os dados apresentados no Quadro 4 não sejam específicos para a rede urbana e estado do Paraná, é possível ter uma ideia dos valores movimentados. 


\section{Quadro 4 - Alguns títulos/direitos creditórios do Agronegócio, Brasil: 2004-2016/fev (R\$)}

\begin{tabular}{l|c|c|c|c|c|c|c|c|c|c}
\hline & \multicolumn{2}{|c|}{2004} & \multicolumn{2}{c|}{2005} & \multicolumn{2}{c|}{2010} & \multicolumn{2}{c|}{2014} & \multicolumn{2}{c}{31 mar. 2016} \\
\cline { 2 - 11 } & n. títulos & $\mathrm{R} \$$ & n. títulos & $\mathrm{R} \$$ & $\mathrm{n}$. títulos & $\mathrm{R} \$$ & n. títulos & $\mathrm{R} \$$ & $\mathrm{n}$. títulos & $\mathrm{R} \$$ \\
\hline LCA & 0 & 0 & 19 & $\begin{array}{c}29 \\
\text { mi- } \\
\text { Ihões }\end{array}$ & 86 & $\begin{array}{c}297,7 \\
\text { milhões }\end{array}$ & 613.135 & $\begin{array}{c}107,5 \\
\text { bilhões }\end{array}$ & 1.142 .057 & $\begin{array}{c}137,9 \\
\text { bilhões }\end{array}$ \\
\hline CDCA & 0 & 0 & 0 & 0 & 18 & $\begin{array}{c}62,9 \\
\text { milhões }\end{array}$ & 73 & $\begin{array}{c}1,6 \\
\text { bilhão }\end{array}$ & 56 & $\begin{array}{c}1,5 \\
\text { bilhão }\end{array}$ \\
\hline CPR & 40.875 & $\begin{array}{c}3,18 \\
\text { bilhões }\end{array}$ & 34.068 & $\begin{array}{c}2,4 \\
\text { bilhões }\end{array}$ & 5.723 & $\begin{array}{c}836,4 \\
\text { milhões }\end{array}$ & 5.551 & $\begin{array}{c}2,9 \\
\text { bilhões }\end{array}$ & 6.497 & $\begin{array}{c}5,9 \\
\text { bilhões }\end{array}$ \\
\hline $\begin{array}{l}\text { cédula } \\
\text { rural } \\
\text { pignoratícia }\end{array}$ & 0 & 0 & 0 & 0 & 1.631 & $\begin{array}{c}134 \\
\text { milhões }\end{array}$ & 956.829 & $\begin{array}{c}58,9 \\
\text { bilhões }\end{array}$ & 940.350 & $\begin{array}{c}55,4 \\
\text { bilhões }\end{array}$ \\
\hline \begin{tabular}{l} 
total Brasil \\
\hline
\end{tabular} & 40.875 & $\begin{array}{c}3,18 \\
\text { bilhões }\end{array}$ & 34.108 & $\begin{array}{c}2,4 \\
\text { bilhões }\end{array}$ & 12.596 & $\begin{array}{c}2,88 \\
\text { bilhões }\end{array}$ & 2.122 .069 & $\begin{array}{c}230,7 \\
\text { bilhões }\end{array}$ & 2.986 .799 & $\begin{array}{c}300,2 \\
\text { bilhões }\end{array}$ \\
\hline
\end{tabular}

fonte: BMEFBovespa (2016).

LCA: letra de crédito do agronegócio; CDCA: certificado de direitos creditórios do agronegócio; CPR: cédula do produto rural.

Dos títulos presentes no Quadro 4, destaque para a cédula do produto rural, instituída em 1994 como um mecanismo de obtenção de crédito rural sem a participação do Estado, para o qual há vasta bibliografia a analisar os efeitos, circunstâncias, contradições. Em 2001 ocorreu alteração na legislação; em 2004 novas regulamentações sobre a financeirização da agropecuária no Brasil. Essa última trata da criação de diversos outros títulos no caminho da ampliação da financeirização da agropecuária. A CPR foi a primeira forma de obtenção de crédito sem a participação do Estado em etapa recente no Brasil, é um instrumento de financiamento da produção e da comercialização da produção, emitida por produtores rurais, suas associações e cooperativas de produção. Em outros termos, é um tipo de contrato em que o produtor recebe antecipadamente dado valor correspondente a certa quantidade de produto a ser entregue na safra, por determinada taxa de juro. Nesse caso, trata-se da CPR física. Mas há ainda a modalidade financeira (instituída em 2001), em que ocorre o mesmo processo, à exceção de que a liquidação do título é em dinheiro, e não em produtos. Nesse caso, ocorre a conversão do valor do produto no momento de vencimento do contrato.

Na realidade há vários títulos vinculados aos agronegócios, mas acima de tudo trata-se da financeirização da agropecuária nacional. Para entender alguns aspectos da expansão da financeirização dos complexos de agronegócios, importa saber que a agropecuária moderna vem sendo realizada com muito mais capital, estando inserida na lógica de expansão da reprodução ampliada do capital. Isso significa que a "[... lógica de reprodução ampliada do capital é lastreada na ação tipicamente capitalista de aplicar dinheiro (D) na produção de mercadorias (M) para obter mais dinheiro (D')" (Gonçalves, 2005, p. 8).

No que tange à financeirização, esta começou a ser realizada nos anos 1960, quando o Estado passou a ofertar crédito subsidiado, como um instrumento de políticas para a agricultura, que vigorou de modo geral até anos 1980. A partir de então com o esgotamento dessa estrutura de financiamento (cujas razões são complexas e envolvem diferentes aspectos das 
políticas macroeconômicas brasileiras), o encaminhamento foi dado no sentido da "[...] inserção crescente da agricultura na lógica do sistema financeiro, primeiro para obtenção de crédito barato e depois para outras movimentações financeiras" (Gonçalves, 2005, p. 20). Emergiram então outros mecanismos de venda antecipada e crescimento do mercado futuro, colocando esses de modo estáveis e consistentes na lógica do desenvolvimento capitalista. Pelo fato destes papéis incorporarem a opção de financiamento da produção, que se associa a riscos reduzidos em termos de preços, geram "[...] estabilidade para a perenidade de investimentos em inovação, a oferta de papéis nas bolsas de mercadorias associadas a outras formas de fazer posição, numa economia de contratos, representa elemento estratégico da espinha dorsal do novo padrão de financiamento [...]" (Gonçalves, 2005, p. 20).

É neste percurso que parcela da agropecuária vem encontrando financiamento para suas atividades, como custeio, capital de giro das agroindústrias e parcela de investimentos. São, portanto, captações lastreadas "[...] em títulos financeiros de recebíveis dos agronegócios, em contratos de entrega futura com agroindústrias de processamento e traders e, ainda de contratos de compra de insumos prazo safra com agroindústrias de insumos" (Gonçalves, 2005, p. 23).

Mas qual a relação desses elementos com a rede bancária? Se Gonçalves (2005) chamava a atenção para a perspectiva de expansão da financeirização da agropecuária em 2005, ela foi muito fortalecida até fevereiro de 2016, conforme dados apresentados. No entanto, é preciso considerar que parcela desse processo se vincula a Bolsas de Valores, mas, outra parcela vincula-se diretamente aos bancos e agências localizadas na rede urbana do Norte do Paraná. Especificamente a CPR física e financeira, muito embora não seja possível obtenção de dados do quanto essas modalidades de títulos sejam movimentadas pelos bancos e pelo sistema de crédito cooperativo.

Os elementos discutidos demonstram formas diferenciadas de obtenção de crédito, dos quais parcela é para investimentos, seja pelo produtor, cooperativa ou associação; demonstram ainda caminhos da financeirização da produção propriamente dita; demonstram também que mesmo ocorrendo redução de agências bancárias, há forte presença dos bancos públicos (36,16\% das agências e 49,83\% de postos de atendimento) com destaque para o Banco do Brasil; as unidades de atendimento do sistema cooperativo também efetuam negociações da CPR.

O segundo elemento a ser referido em direção à expansão do crédito no período 20032013, vincula-se ao Programa Minha Casa, Minha Vida. Em Londrina de todas as modalidades de construção e produção de moradias legalizadas (casas, apartamentos, conjuntos habitacionais e casas em condomínios), 8,8\% de um total de 58.336 unidades foi construída por pequenos produtores individuais, como casas geminadas com área de $45 \mathrm{~m}^{2}$ a $50 \mathrm{~m}^{2}$, em terrenos de $250 \mathrm{~m}^{2}$, legalizadas, cujo consumidor a adquiria por intermédio de financiamento bancário (Fresca, 2015). Nessa relação, o crédito para investimentos e articulações com a rede urbana e rede bancária demonstra que, o crédito para investimento tem relação direta com o desenvolvimento da economia, porque significam investimentos na produção, crescimento da renda, emprego, aumento do consumo das famílias. Em 1994, a relação crédito/PIB era de 35\%; em 2002 foi de 22\%; em 2013 foi de 56,5\%; a partir da última data começou a ser reduzida. 
De acordo com o Dieese (2015), o saldo de crédito teve crescimento de 15,5\% para pessoas jurídicas e 104,4\% para pessoas físicas e até 2007 era ofertado predominantemente pelos bancos privados. A partir de então os bancos públicos passaram a ter maior participação, sejam eles livres ou direcionados, com expansão de 176\% entre 2008-2013. Dos recursos livres para pessoas jurídicas, a maior parcela foi destinada para capital de giro, enquanto para pessoas físicas foi assim utilizado: crédito consignado com 21\% em 2008 e 29\% em 2013; aquisição de veículos ampliados de 25\% para 29\% nas datas referidas e o cartão de crédito teve elevação de 12 para 19\% entre 2008-2013 (Dieese, 2015).

O crédito para famílias implica em satisfação de demandas reais ou criadas e pode ser vinculado à creditização do território (Santos, 1993). Bielschowsky (2012), ao discutir estratégias de desenvolvimento para o Brasil, aponta que há três motores básicos de investimentos: o consumo de massa, recursos naturais e infraestrutura. Com relação ao consumo de massa, o autor correlaciona com melhoria da distribuição de renda, ampliando consumo e com uma estrutura produtiva capaz de realizar no país boa parte da produção em larga escala, correspondente nos setores primário, industrial e de serviços sem prejuízo de ampliar a exportação. Nesse sentido o consumo de massa também se vincula aos investimentos produtivos. Chama atenção a expansão do crédito para capital de giro referida anteriormente. Portanto, o consumo de massa é parte integrante do processo de articulação com o sistema bancário. Por isso, o crédito para investimento demonstra dinâmicas distintas de produção, de apropriação, de diferenciação espacial, articuladas ao econômico, social e político. Não importa se é para produzir soja ou mel - apenas para manter correlação com a agropecuária - de qualidades distintas, são produtos fundamentalmente para o mercado e adentram no circuito do crédito.

\section{Considerações finais}

O sistema bancário presente na rede urbana do Norte do Paraná demonstrou no período considerado tendências relativamente diferenciadas daquelas verificadas para o Brasil e o estado do Paraná, com relativa redução de agências para bancos comerciais e ampliação de postos de atendimento. Mas, de modo oscilante e vinculado à dinâmica econômica nacional, a distribuição desses tipos de unidades de atendimento bancário nas cidades da rede urbana segue padrão de forte correlação com os níveis de centralidade: maior centralidade, maior número de agências e postos. Apreende-se ainda o aumento da exclusão de cidades do acesso a agências, salvo a expansão do sistema cooperativo de crédito em pequenas cidades profundamente articuladas com as atividades agropecuárias e industriais, que se colocam como nichos de mercado, onde bancos múltiplos não conseguem expansão, apontando concorrência bancária com o sistema cooperativo - uma das faces ainda pouco trabalhadas nessa ampla temática.

\section{Referências}

ASALIN, G. A. Gênese e dinâmica de três cidades na rede urbana de Maringá:

Paranavaí, Nova Esperança e Nova Aliança do Ivaí. Tese (Doutorado em Geografia) - Centro de Ciências Humanas, Letras e Artes, Universidade Estadual de Maringá, Maringá, 2015. 
BCB. BANCO CENTRAL DO BRASIL. Anuário estatístico do crédito rural (Até 2012). Disponível em: http://www.bcb.gov.br/?RELRURAL. Acesso em: 12 mar. 2016a.

\section{Relação de agências, postos e filiais de administradoras de Consórcio} (transferência de arquivos). Disponível em: http://www.bcb.gov.br/fis/info/agencias.asp. Acesso em: 15 mar. 2016b.

BIELSCHOWSKY, R. Estratégia de desenvolvimento e as três frentes de expansão no Brasil: um desenho conceitual. Economia e Sociedade, Campinas, v. 21, p. 729-747, dez. 2012. Número especial.

BMEFBOVESPA. Registro de títulos e operações: títulos e direitos creditórios do agronegócio. Disponível em: http://www.bmf.com.br/bmfbovespa/pages/boletiml/Estatisticasibalcao.asp. Acesso em: 12 mar. 2016.

BOLSA BRASILEIRA DE MERCADORIAS. Quem somos. Disponível em: https:/www. bbmnet.com.br/quem-somos/a-bolsa. Acesso em: 31 mar. 2016.

BOLSA DE CEREAIS E MERCADORIAS DE LONDRINA. Institucional. Disponível em: http://www.bcml.com.br/institucional/. Acesso em: 31 mar. 2016.

CONTEL, F. B. Território e finanças: técnicas, normas e topologias bancárias no Brasil. Tese (Doutorado em Geografia) - Faculdade de Filosofia, Letras e Ciências Humanas, Universidade São Paulo, São Paulo, 2007.

CORRÊA, R. L. Redes geográficas: reflexões sobre um tema persistente. Cidades, Presidente Prudente, v. 9, n. 16, p. 199-218, 2012.

Trajetórias geográficas. Rio de Janeiro: Bertrand Brasil, 1997.

A rede urbana. São Paulo: Ática, 1989.

Repensando a teoria dos lugares centrais. In: SANTOS, M. (Org.). Novos rumos da geografia brasileira. São Paulo: Edusp, 1982. p. 50-65.

CHRISTALLER, W. Central places in southern Germany. Englewood Cliffs, N.J.: Prentice-Hall, 1966.

DIAS, L. C.; LENZI, M. H.; CORIGLIANO, L. de S. T. Reorganização espacial de redes bancárias no Brasil: concentração financeira e expansão territorial. Revista Geográfica de America Central, Costa Rica, v. 2, p. 1-15, 2011. Número especial.

DIEESE. A evolução do crédito na economia brasileira: 2008-2013. Nota Técnica. São Paulo, n. 135, p. 1-31. Disponível em: https://www.dieese.org.br/notatecnica/2014/notaTec135Credito.pdf. Acesso em: 25 jul. 2015.

ENDLICH, A. M. Pensando os papéis e significados das pequenas cidades do noroeste do Paraná. 1996. 505 f. Tese (Doutorado em Geografia) - Faculdade de Ciências e Tecnologia, Universidade Estadual Paulista, Presidente Prudente, 1996.

FRESCA, T. M. Agentes que produzem o espaço urbano: discussão sobre pequenos construtores de casa. Mercator, Fortaleza, v. 14, n. 4, p. 45-61, dez. 2015. Número especial. 
A rede urbana do norte do Paraná. Londrina: Eduel, 2004.

A rede urbana do norte do Paraná: de um padrão tipo christalleriano à uma condição de diversidade e complexidade. In: FRESCA, T. M.; SALVI, R. F; ARCHELA, R. S. (Org.). Dimensões do espaço paranaense. 1. ed. Londrina: Eduel, 2002. p. 1-28. v. 1 .

GONÇALVES, J. S. Agricultura sob a égide do capital financeiro: passo rumo ao aprofundamento do desenvolvimento dos agronegócios. Informações Econômicas, São Paulo, v. 35, n. 5, p. 7-36, 2005.

IBGE. INSTITUTO BRASILEIRO DE GEOGRAFIA E ESTATÍSTICA. Regiões de influência das cidades: 2007. Rio de Janeiro: IBGE, 2008.

. Regiões de influência das cidades: 1993. Rio de Janeiro: IBGE, 2000.

OLIVEIRA, E. X. G. de. Perspectivas das pesquisas sobre regiões de influência das cidades. In: PEREIRA, E. M.; DIAS, L. C. D. As cidades e a urbanização no Brasil: passado, presente e futuro. Florianópolis: Insular, 2011. p. 116-128.

PORTAL DO COOPERATIVISMO FINANCEIRO. Instituições financeiras cooperativas cresceram em $16 \%$ o volume de depósitos em 2015. Disponível em: http://cooperativismodecredito.coop.br/2016/04/instituicoes-financeiras-cooperativas-cresceram-em-16-o-volume-de-depositos-em-2015/. Acesso em: 30 abr. $2016 \mathrm{a}$.

Sistema Sicoob. Disponível em: http://cooperativismodecredito.coop.br/cenario-mundial/cenario-brasileiro/dados-consolidados-dos-sistemas-cooperativos/sistema-sicoob/. Acesso em: 20 mar. 2016b.

Sistema Sicredi. Disponível em: http://cooperativismodecredito.coop.br/cenario-mundial/cenario-brasileiro/dados-consolidados-dos-sistemas-cooperativos/sistema-sicredi/. Acesso em: 25 mar. 2016c.

SANTOS, M. A natureza do espaço: técnica e tempo, razão e emoção. São Paulo: Hucitec, 1996.

Urbanização brasileira. São Paulo: Hucitec, 1993.

UNIPRIME. Agências Uniprime. Disponível em: https://www.uniprimebr.com.br/\#agencias. Acesso em: 31 mar. 2016. 